\title{
"A dor e o incômodo são passageiros, mas o orgulho é eterno": incitação e evitação da dor entre atletas de ultramaratona
}

Isabel Siqueira ${ }^{1}$

Universidade do Estado do Rio de Janeiro

Resumo: Com o objetivo de analisar a experiência da dor entre atletas de ultramaratona, o artigo aborda significados da dor e estratégias para lidar com as sensações dolorosas a partir da análise de entrevistas com atletas de ultramaratona e pesquisa de campo em uma prova de ultramaratona de 235 quilômetros, no estado de Minas Gerais no ano de 2016.

Palavras-chave: dor; ultramaratonas; esporte. 


\title{
"Pain and nuisance are passengers, but pride is eternal": incitement and avoidance of pain among ultramarathon athletes
}

\begin{abstract}
With the objective of analyzing the experience of pain among ultramarathon athletes, the article addresses meanings of pain and strategies to deal with painful sensations from the analysis of interviews with ultramarathon athletes and field research in a $235 \mathrm{~km}$ ultramarathon, in the state of Minas Gerais in the year 2016.
\end{abstract}

Keywords: pain; ultramarathons; sport.

\section{"El dolor y la molestia son pasajeros, pero el orgullo es eterno": incitación y evitación del dolor entre los atletas de ultramaratón}

Resumen: Con el objetivo de analizar la experiencia del dolor entre atletas de ultramaratón, el artículo aborda los significados del dolor y las estrategias para lidiar con las sensaciones dolorosas del análisis de entrevistas con atletas de ultramaratón y la investigación de campo en un ultramaratón de 235 kilómetros, en el estado de Minas Gerais en el año 2016.

Palabras clave: dolor; ultramaratones; deporte. 
$\mathrm{O}$ presente trabalho analisa os dados coletados em pesquisa qualitativa com ultramaratonistas (observação participante em uma prova de ultramaratona de 235 quilômetros, realizada em Minas Gerais em julho de 2016, e entrevistas de roteiro semiestruturado, realizadas em agosto do mesmo ano), com o objetivo de tecer uma análise da experiência de dor entre ultramaratonistas, observando as estratégias utilizadas para a superação, evitação ou gestão da sensação dolorosa durante uma prova e os significados e usos sociais da dor neste contexto.

Ultramaratona é toda corrida com distância superior à de uma maratona, ou seja, são corridas acima de 42,195 quilômetros - no Brasil as menores competições costumam ter 50 quilômetros e as maiores estendem-se por 450 quilômetros. Os terrenos escolhidos costumam ser estradas não pavimentadas, trilhas e ambientes de baixa urbanização. Devido a seu caráter fisicamente extenuante, a ultramaratona está intrinsecamente ligada à sensação dolorosa ou à possibilidade dessa sensação, evidenciando o jogo de negociação do aleta com a dor, com seus aspectos sociais e culturais.

No universo dos ultramaratonistas, o campo semântico da "dor" agrega termos como "sofrimento", "enjoo", "tontura”, "cansaço", "fadiga”, entre outros que denotam todo o desafio a ser superado para tornar-se ultramaratonista. "A dor e o incômodo são passageiros, mas o orgulho é eterno" é uma frase cunhada pelo ultramaratonista Marcio Villar, amplamente conhecida pelos praticantes desse esporte, chegando até a ser tatuada por alguns deles, evidenciando a construção da identidade desse tipo de atleta está imbricada em sofrer e superar esse sofrer. Assim, a dor destaca-se como socialmente inscrita, tornando esse fenômeno possível de ser entendido a partir de sua perspectiva social.

\section{Dor}

A palavra dor surge nas narrativas dos ultramaratonistas tanto para se referir a uma sensação forte e difusa por todo o corpo, como "eu era uma dor só" (VILLAR, 2015: 106), quanto se referindo a sensações localizadas, mais ou menos brandas, como se vê em "Os dedos dos pés estourados e o dedão machucado doíam bastante" ou "com o joelho machucado na queda ainda doendo" (VILLAR, 2015: 108).

Ao estudar ultramaratonistas mulheres nos EUA, a educadora física Hanold (2010) observa que a dor é classificada seguindo uma gradação de intensidades. As participantes descreveram três níveis distintos de dor durante os treinos: "desconforto", "dor boa" e "dor ruim". O "desconforto" e a "dor boa" são percebidos como dores inofensivas e não suscitam nenhuma alteração na rotina de treinamento; já a “dor ruim” é entendida como um "alerta” do corpo, levando-as a parar 
o treino e procurar ajuda de profissionais de saúde. Diferentes classificações para dor também são encontradas por Cesar Sabino e Madel Luz (2014) em pesquisa sobre praticantes de fisiculturismo em academias de musculação do Rio de Janeiro. Os autores observaram a existência das dores positivas e das prejudiciais: enquanto a primeira aponta para a execução correta dos exercícios físicos e é parte inexorável do desenvolvimento muscular, a segunda dor surge como "fruto de excessos e execuções equivocadas" (SABINO e LUZ, 2014: 474). O mesmo termo designa diferentes experiências que levam a diferentes reações, dores que são qualificadas e adjetivadas.

Entre ultramaratonistas, dor é uma palavra usada para descrever tanto uma sensação levemente incômoda e muito comum após um treino, quanto uma sensação forte e inesperada o bastante para ser compreendida como um indicador de lesão fisicamente limitante. Essas diferentes formas de doer teriam a mesma natureza, diferenciando-se entre si apenas por distintas gradações? Em outras palavras, existe a Dor, no singular, como algo dado na natureza, que varia em intensidade de acordo com o estímulo a que o corpo é submetido?

Em Story of Pain, Joanna Bourke (2014) parte do princípio de que dor é aquilo que sente a pessoa que reivindica para si essa sensação, ou seja, qualquer pessoa que alega estar "com dor" sente dor, compreendendo o doer como o encontro pessoal e único com um sofrimento. Trata-se, em sua leitura, de uma condição auto atribuída, ainda que, no entanto, se precise levar em conta chancelas sociais do que venha a ser dor, para que esta tenha reconhecimento público. Inspirada pelos jogos de linguagem de Wittgenstein, Bourke considera as emoções em termos de práticas culturais altamente dinâmicas e defende a ideia de que o ser-em-dor requer um momento de consciência do sofredor e/ou da testemunha. Partindo desse ponto, a historiadora entende que "dor" não descreve o que é experimentado, mas sim a maneira como experimentamos algo.

Por caminhos distintos, em certo sentido a posição da historiadora mostra-se em consonância com a assumida pela Associação Internacional de Estudos da Dor (International Association for the Study of Pain - IASP) - uma instituição formada por cientistas, profissionais de saúde e profissionais de políticas públicas com o objetivo de estimular pesquisas sobre dor para expandir as políticas de alívio da dor pelo mundo -, que define dor de maneira multifatorial e relacional, sendo "uma experiência sensorial e emocional desagradável associada ao dano tecidual real ou potencial, ou descrita em termos de tais danos". Em nota complementar à definição, a IASP esclarece que a dor é subjetiva e relacional, uma experiência emocional que não está necessariamente ligada a um estímulo que cause ou possa causar danos aos tecidos.

Bourke propõe a compreensão da dor como um "tipo-de-evento" (type-ofevent). Compreender o estar-em-dor como um tipo-de-evento permite-nos perceber que tal estado não emerge exclusivamente dos processos fisiológicos ainda que tais processos tenham grande importância -, mas também na negociação com mundos sociais e culturais. Tal abordagem evita que haja a reificação da dor como uma entidade ou uma coisa monolítica, identificável e independente. Essa perspectiva também aponta o aspecto avaliativo do estar-em-dor, no sentido de que só existe em termos de significado e avaliação. Sob a concepção de um tipo-de-evento, a dor é considerada uma atividade. As pessoas doem de maneiras diversas, uma vez que se dói em diferentes contextos ambientais e relacionais. Doer, esta é a perspectiva na qual me embaso aqui, é sempre contextual. Dessa 
forma, estímulos nociceptivos podem levar a expressões de sofrimento ou de prazer, como o contraste proposto nos exemplos dados por Bourke (2014: 30) do castigo corporal e do masoquismo.

\footnotetext{
Pain may be rendered significant because it is unpleasant but there is no phenomenological state that is in and of itself 'bad', as any zealous saint or (indeed) keen sadomasochist will tell you. Again, this is not to deny that sensations may be important, but they tell only part of the story and, in many instances, a minor part.
}

As formas de estar-em-dor envolvem processos linguísticos, ambientais, agentes e relações complexas com outros corpos. E, de acordo com Bourke (2014), só pode ser entendida enquanto um 'estar em dor', ou seja, sua compreensão se dá em relação à maneira como afeta o estado de ser das pessoas. A historiadora não nega, ao contrário, ela reafirma a importância da natureza sensorial da dor ("after all, pain is "what hurts"' [BOURKE, 2014: 29]), mas refuta a ideia de que a sensação dolorosa se resume à resposta a um estimulo sensório. Doer pode, então, ser mais a repercussão de uma resposta ao evento do que um efeito sensorial em si. Existe uma construção na dor que permite com que situações que pareçam dolorosas não sejam exatamente dolorosas, da mesma forma com que situações que não pareçam dolorosas sejam extremamente dolorosas em certos contextos.

Não existe um corpo natural e pré-cultural aguardando inscrições sociais, corpos são agentes ativos na criação de mundos sociais, ao mesmo tempo em que são criados por esses mundos, uma ideia já demonstrada de forma exaustiva pelo campo da antropologia do corpo (MAUSS, 1974; CSORDAS, 2008; LE BRETON, 2010). Da mesma forma, dor não deve ser compreendida como uma entidade exclusivamente natural.

Como defende Bourke (2014), as interações sociais e ambientais, comportamentos culturais e sistemas de linguagem não são entidades independentes umas das outras, mas sim existem em relação às outras. A saúde e a doença não são eventos isolados, tampouco de uma estrita manifestação da natureza, mas sim do produto da interação entre a mente e os corpos individual, social e político. Em outras palavras, uma forma de comunicação, a "linguagem dos órgãos" falada simultaneamente pela natureza, a sociedade e a cultura.

Estar-em-dor não é diferente de outras práticas do eu: os componentes cognitivos, perceptivos, emocionais, avaliativos e sensuais da pessoa estão bastante entrelaçados. Dessa forma, o modelo proposto por Bourke em sua história da dor supera as dicotomias entre dor física e sofrimento mental. Estudos em neurociências compartilham dessa visão e vêm defendendo que os mesmos centros cerebrais que processam a dor corporal também são ativados com sofrimento emocional. A dor psicológica ou mental sempre envolve eventos físicos - neuroquímicos, musculares e nervosos, entre outros. O sofrimento psíquico pode ser doloroso e fenomenologicamente parecido com a dor física, devendo, portanto, ser classificado da mesma maneira (BIRO, 2010). A dor física, em contrapartida, provoca um desvio do curso esperado da vida da pessoa, interrompendo de maneira menos ou mais marcante as biografias (BURRY, 1982). No mesmo sentido:

a experiência de uma disrupção das formas e funções regulares da pessoa, implica necessariamente o 'sofrimento', quer se o entenda no sentido 'físico' mais estrito, quer se o entenda no sentido 'moral', abrangente (...) e que engloba, inclui, o sentido físico. (DUARTE, 1998: 13) 
Nos termos da autora, "The body is mind-ful and the mind is embodied" (BOURKE, 2014: 41). Ao borrar as fronteiras entre corpo e mente, borram-se também as fronteiras entre dor e sofrimento.

\section{Ultramaratonas}

Ultramaratonas nunca são chamadas de competição, mas sim de "prova" ou "desafio". Aquele que a completa dentro do tempo previsto é "finisher"; quem desiste da prova a abandona porque "quebrou". Um atleta pode "quebrar na mente" ou "no corpo": se ele acredita que as dores sentidas o impedirão de permanecer no percurso, mas seus pares - ou até mesmo ele, posteriormente creem que existem condições de seguir na prova, diz-se que "quebrou na mente"; já a ideia de "quebrar no corpo" é acionada quando alguma lesão ou episódio de desidratação é irreversível naquele momento, conferindo risco de vida ou de sequelas permanentes ao "ultra", diminutivo usado com frequências por atletas.

É comum, mas não obrigatório, que ultramaratonistas corram assessorados por uma equipe de apoio, formadas geralmente por amigos também ultramaratonistas e familiares do atleta, além de profissionais de saúde, geralmente fisioterapeutas ou educadores físicos. Aqueles que prescindem de apoio são chamados "survivor" e devem contar apenas com a ajuda da organização do evento.

As ultramaratonas não compreendem um grupo social homogêneo, tendo entre seus adeptos pedreiros e grandes empresários; isso não significa que se trate de uma modalidade absolutamente democrática, já que as diferenças podem aparecer em diversos mecanismos de distinção. Tal diversidade pode ser percebida pelo tipo de equipamento utilizado, com maior presença de equipamentos eletrônicos (GPS, smartwatches e frequencímetros, por exemplo) e de estrutura de equipe de apoio (carros 4x4, tendas para descanso, acessórios para cozinha), mas não se configura como algo predominante e hegemônico, uma vez que é muito comum que os participantes de menor poder aquisitivo recebam ajuda de diversas fontes - desde ultramaratonistas de classes mais altas até parentes, amigos e pequenos comerciantes que admiram seus feitos. De toda forma, a disparidade na qualidade dos equipamentos não se evidencia como fator de distinção entre os participantes durante a prova em si, período compreendido entre a largada e a linha de chegada. De maneira semelhante aos fisiculturistas estudados por Sabino e Luz (2014), os atletas de classes sociais mais altas tendem a possuir mais equipamentos eletrônicos do que aqueles de classes mais baixas. Isso não se apresenta como uma regra geral e, como dito anteriormente, também não causa distinções entre eles quando estão em prova, afinal "quem tem talento, não precisa de equipamento". Essa frase é comum entre muitos atletas amadores de esportes de alta performance e traz em si a ideia de que o principal instrumento daquele atleta é ele mesmo.

\section{Instrumentos internos e instrumentos externos}

No que tange aos usos do corpo no esporte (BOURDIEU, 1983), a ultramaratona não prescinde de instrumentos. Os tênis são o principal instrumento do corredor, mas existem também os equipamentos que a organização de cada prova solicita aos seus participantes, como mochila de hidratação, apito e manta térmica, entre outros itens que compõem os instrumentos de uso externo. Além dos instrumentos de uso externo, também existem os instrumentos de uso interno, como medicamentos analgésicos, bebidas isotônicas e suplementos alimentares 
de diversos tipos, como carboidratos em gel, shakes de proteína, cápsulas de sal ou de cafeína, utilizados com frequência por ultramaratonistas durante uma prova.

Ao tratar sobre o que opto por chamar aqui de instrumentos internos, é importante ressaltar que as provas de ultramaratona não possuem política ou testagem antidoping. As estratégias e técnicas para o uso de substâncias lícitas ou ilícitas é compartilhado publicamente entre os atletas. O conhecimento e a troca pública sobre os usos dos instrumentos internos pode ser o fator que torna o uso de substâncias como a cafeína, proibida em algumas modalidades, um instrumento de uso corriqueiro entre os ultras. Afinal, a ideia de injustiça do doping é também baseada no desconhecimento de outros atletas acerca das substâncias utilizadas e utilizáveis, o que geraria uma inequidade nas condições competitivas entre os atletas (CONRAD, 2007).

Há também a ideia de que provas de corrida como estas expõem o corpo a uma atividade de intensidade superior ao que seria saudável. Os instrumentos internos passam a ser consumidos com o objetivo de restaurar a homeostase do corpo durante a prova. A cafeína, por exemplo, seja consumida em cápsulas ou em copos de café preto, é entendida como um ponto de apoio necessário para provas mais longas, quando a noite ou próprio cansaço trazem o sono, condição indesejável no momento da prova. Ainda que cientes do discurso médico sobre a necessidade de dormir cerca de oito horas por dia, muitos atletas passam 24 horas ou mais acordados para completarem suas corridas. A cafeína seria, então, capaz de restaurar o funcionamento regular do corpo quando em estado de alerta. A substância, como os demais instrumentos internos, não o faria ir além de suas condições regulares em estado de alerta, ela apenas serviria para restaurar esse estado nos momentos em que o corpo parece rebelar-se contra os objetivos traçados pelo indivíduo. Os instrumentos internos não atuam como uma forma de aprimoramento para além do que consideram o funcionamento regular do corpo humano, tampouco são de uso secreto ou clandestino. Desse modo, não são classificados como doping, atividade carregada de moralidade negativa, compreendida por grande parte do meio esportivo como uma enganação aos seus pares e a si mesmo (MØLLER, 2008; HENNING, 2014; MORAES et al, 2015).

\section{Prazer em correr}

As histórias ouvidas sobre como ultramaratonistas começaram a correr costumam envolver motivos como estética e saúde. E existe de fato uma relação entre adesão ao exercício físico e a busca por um ideal de saúde ou de aparência física, a construção de um projeto estético de si. De acordo com Ortega (2005), essa procura está ligada à bio-ascese, ou seja, ao deslocamento de uma subjetividade a outra centrado na disciplina do corpo como ponto central do estilo de vida do sujeito.

Segundo Deborah Lupton (2000), nas culturas ocidentalizadas o estilo de vida tem um significado positivo, ligado à individualidade do sujeito, ao projeto estético de si mesmo e atua como um dos principais recursos na construção de sua subjetividade. Assim, pode-se compreender a adesão ao estilo de vida ativo não apenas como a expressão de um comprometimento com a própria saúde, mas sim (ou também) com determinados valores estéticos e outras moralidades associadas à atividade física.

Se os ultramaratonistas contam que se iniciaram na corrida por questões de saúde ou para perder massa gorda, sua evolução para ultramaratonas nunca está 
associada a essa busca. Os dados desta pesquisa apontam para motivações para além do sacrifício e de uma ascese corporal. Existem dois aspectos primordiais na escolha da ultramaratona como modalidade esportiva que dialogam de forma peculiar com as concepções nativas de dor: a busca pelo desenvolvimento da força mental e o prazer.

A ideia de superação e de força mental associada à identidade do ultramaratonista parece levar o sujeito, a cada prova, a uma percepção de si como mais forte e capaz de lidar com os desafios da vida cotidiana. Neste sentido, dialoga com a relação que Lupton constrói entre estilo de vida, saúde e prática esportiva. Ao mesmo tempo, parece impor um constante ritual de passagem aos sujeitos, que se socializam enquanto ultramaratonistas em etapas, marcas de novos desafios vencidos que podem inclusive se inscrever no corpo através de tatuagens.

Entretanto, conceitos como o de bio-ascese (ORTEGA, 2005) não dão conta plenamente da adesão a exercícios físicos porque negam um aspecto importante: o prazer. É importante notar que o esporte hoje é uma das principais formas de lazer e fontes de prazer. Para compreender como ocorre a oposição prazer-sofrimento, faz-se necessária uma análise do esporte como produtor de prazer.

O “dispositivo da sensibilidade", desenvolvido por Duarte (1999: 25), oferece uma chave teórica adequada para começar a pensar a dimensão do prazer no esporte. No "dispositivo da sensibilidade", os "sentidos estão tanto na raiz da razão como na da 'imaginação' ou das 'emoções' e 'paixões'”. Três elementos estruturam-se no dispositivo da sensibilidade: a perfectibilidade, a experiência e o fisicalismo. A perfectibilidade é a ideia de que o sujeito pode aperfeiçoar-se continuamente, não havendo limites para seu progresso e suas transformações. Esse progresso só se dá a partir da experiência. É através de seus sentidos que o indivíduo entra em contato com o mundo exterior e, a partir de suas experiências, faz germinar em si o aprimoramento da razão. A experiência, o contato com o que "está fora" ocorre a partir de um corpo destacado do espírito, que possui uma lógica própria passível de ser desvendada, que Duarte (1999: 25) defende como constituindo "a consideração da corporalidade em si, como dimensão autoexplicativa do humano, que se pode chamar propriamente de fisicalismo”. Maximizar a vida e otimizar o corpo estruturam-se no e são estruturadas pelo dispositivo da sensibilidade e nele assumem sentidos opostos: a maximização da vida e a otimização do corpo concentradas na intensidade imediata ou concentradas na continuidade máxima.

A intensidade constrói-se junto às ideias de singularidade e de experiência, sob o ideário romântico que permeia as sociedades ocidentais. "Cada momento de um ente ou da dimensão de um fenômeno tem sua própria intensidade, incomparável com as que se expressam em outros tempos e espaços" (DUARTE, 2004: 10). Correr para extrair de cada dia o máximo de prazer que puder é o que muitos ultramaratonistas parecem buscar. A concepção de "viver a vida ao máximo" liga-se diretamente à ideia de prazer e essa é uma dimensão importante para o salto de maratonista a ultramaratonista. Marcio Villar (2015: 21) narra essa transição, dizendo que "correr para mim já não era somente uma forma de permanecer magro, era algo que me fazia bem, me dava prazer".

Do mesmo modo, é bastante frequente ouvir ultramaratonistas localizarem a partir de quantos quilômetros deixam de sentir o incômodo comum da adaptação do corpo ao exercício para atingir o prazer que buscam nessa atividade, é o momento em que "entram na prova" ou o período em que "estão na prova”. Quando precisam, por algum problema de saúde, suspender as atividades de corrida, mos- 
tram-se preocupados por não poderem sentir o que "precisavam sentir". O aspecto do prazer aparece no discurso dos ultramaratonistas entrevistados como o principal motivo para se manter nessa atividade: "só faço porque a ultra é prazerosa"; "independente da distância, de tudo que eu sofra, o êxtase de uma corrida me leva ao extremo de felicidade"; "eu sempre até me emociono quando eu tô numa prova, é gratificante demais. Eu acho que superar o limite, não sei, é prazer maior meu mesmo".

O que se precisa sentir, a "sensação boa”, o prazer, as emoções ligadas à prática esportiva podem ser bem compreendidas a partir da obra de Norbert Elias e Eric Dunning (1992). Os autores apresentam uma visão da prática esportiva ligada às emoções que elas provocam, admitindo a possibilidade de haver fatores biológicos que influenciam a busca por tais emoções. $\mathrm{O}$ esporte pode ser definido como uma competição entre pessoas, que ocorre em caráter individual ou coletivo, realizada de diversas maneiras, mas que mantém a característica principal de confronto e busca de superação. A regulamentação dos jogos, que dá origem ao que conhecemos hoje como esporte, é explicada através da chave analítica do processo civilizador, ocorrido nas sociedades industriais mais complexas, que aumentou tanto o controle social quanto o autodomínio da excitação exagerada. Com a consolidação do Estado moderno, a maioria dos indivíduos passou a nutrir valores mais pacíficos, rejeitando comportamentos tidos como animalescos. Do adulto civilizado espera-se o autodomínio da própria excitação. Acontece, então, "a mudança de ênfase, do desejo de vencer um confronto para a aspiração à vivência da agradável excitação prolongada do confronto" (ELIAS e DUNNING, 1992: 256).

Capaz de provocar uma gama de sentimentos geralmente reprimidos, como a raiva, o medo e a paixão, o esporte, todavia, o faz de modo não ameaçador à ordem civilizada. As emoções fortes e exageradas ocorrem em ambientes controlados, em que tais sentimentos são permitidos e previstos. Extravasam-se as tensões cotidianas nas atividades de lazer, em um efeito catártico restaurador, através de uma "perturbação temporária e passageira da excitação agradável" (ELIAS e DUNNING, 1992: 138). No esporte, o indivíduo tem a sensação de risco presente na hiperexcitação, mas toda a experiência é mais ou menos regulada de acordo com as normas sociais vigentes.

A prática esportiva assume, então, um caráter compensatório, que permite um alívio na vida social ordinária. Alívio porque evoca um tipo especial de tensão e excitação prazerosa, que permite o fluxo de sentimentos aparentemente contraditórios - em ambientes controlados e socialmente aceitos. A busca pela excitação é um traço comum em nossa sociedade. Esse anseio desaparece depois de saciado, mas torna a voltar de tempos em tempos. Elias e Dunning (1992) entendem que tal necessidade possa ter raízes biológicas, mas não a admitem como um fenômeno puro da biologia.

\section{Corpo-mente}

As categorias "prova” e "desafio", mais comuns no universo da ultramaratona, em detrimento de "competição", para se referir aos eventos da modalidade, apontam para o caráter de duelo consigo e não com o outro. Da forma como os ultramaratonistas compreendem a relação entre o atleta e a prática esportiva, a cosmologia da modalidade, há um embate entre sua mente e seu corpo. Em busca da vitória da mente, lança-se em momentos de introspecção durante a prova. Para os ultramaratonistas, o êxito em uma prova está mais na força mental do que na 
capacidade física. Não que os treinamentos físicos não sejam importantes: eles são vistos como necessários e são executados por todos os participantes. Mas a essência de um ultramaratonista, defendem os sujeitos desta pesquisa, está em sua capacidade de dominar a mente para, então, dominar o corpo e cumprir a meta traçada. Isso vale para a condição atlética do sujeito, mas também para a sua lida com as inevitáveis dores que provas tão demandantes costumam gerar. No mundo das ultramaratonas, a relação mente-corpo é colocada de forma que a mente seja englobante do corpo, ela pode dominá-lo e definir até onde ele é capaz de ir.

O corpo obedece, nesta cosmologia, aos desígnios da mente, distinguindo-se os dois não como entidades de igual valor, mas sim como englobado e englobante. Essa perspectiva de análise, que pressupõe um englobado e um englobante, deriva da "teoria das hierarquias", cunhada por Duarte (1986) a partir do exame pormenorizado que faz da obra do antropólogo francês Louis Dumont. A "teoria das hierarquias" trata da universalidade da oposição hierárquica nas classificações, que é permeada por ideias de "valor", "situação" e "nível". Apresenta três postulados básicos: (1) a lógica classificatória não obedece a uma disposição linear, mas preponderantemente a uma lógica hierárquica. Dessa forma, as classificações são permeadas pela ideia de valor, refletindo um universo bidimensional, com planos de significação e espessuras diversos; (2) a bi dimensionalidade do modelo expressa a existência de um nível superior e outro inferior. Um nível englobante, em que existe uma unidade dos termos, e outro englobado, onde ocorre a distinção e a contradição; (3) por fim, a totalidade vista como unidade mínima, propiciando inversões hierárquicas de acordo com a situação.

No caso do par de oposição mente-corpo no universo dos ultramaratonistas, a "mente" aparece no discurso como englobante do "corpo", o que se pode perceber no frequente uso de expressões como "cabeça forte", "mente forte" em oposição a "cabeça fraca", "mente fraca" para se referir à capacidade do atleta de domar seu corpo. Se a dor é um "instrumento mnemônico eficaz que, antes de qualquer coisa, não nos faz esquecer (...) da existência do corpo" (VARGAS, 1998: 130), é preciso que o atleta transcenda o sofrimento e, por conseguinte, o corpo através da força de sua "mente". Um ultramaratonista é essencialmente alguém de "mente forte", que consegue direcionar a mente para a superação de todo sofrimento imposto ao corpo pelas longas distâncias percorridas em uma prova.

A identidade de um ultramaratonista passa diretamente por essa característica: provar que a força da mente é maior do que a incerteza do corpo. Entretanto, há momentos em que o corpo coloca limitações intransponíveis, como um pé fraturado ou uma desidratação profunda. Distinguem-se os limites intransponíveis do corpo daqueles que devem ser ignorados e superados pela mente por meio de uma diferenciação entre atletas já estabelecidos como ultramaratonistas e aqueles que ainda não são estabelecidos como tal. Aqueles estabelecidos como ultramaratonistas podem não terminar uma prova por "cabeça", e ainda assim não terão sua identidade de ultramaratonista posta em xeque. Tampouco quando "quebram no corpo", não são julgados por mau condicionamento ou pouco treinamento, mas sim por algo mais forte que realmente o impede de seguir. Dessa maneira, o status do atleta no esporte influencia diretamente sobre a forma como ele pode se movimentar nas desistências e como ele será avaliado pelos seus pares. 


\section{Evitação da dor}

O aprendizado das maneiras de doer em uma prova acontece principalmente na relação com ultramaratonistas mais experientes. As práticas e saberes são transmitidas também pelos silêncios. Da mesma forma que os fisiculturistas estudados por Sabino e Luz (2014), os ultramaratonistas desenvolvem sua percepção de estar-em-dor a partir de um saber corporal e prático adquirido através de conversas entre si e da observação da performance social dos mais antigos ou bem-sucedidos. A legitimidade de doer é definida pelo grupo social.

O acionamento de estratégias para a evitação da dor também é parcialmente aprendido no contato com outros ultramaratonistas, estando ligado ao conhecimento das necessidades do próprio corpo e dos saberes médicos que as envolvem. Há diferentes estratégias para vencer o sofrimento e elas requerem não somente um domínio de saberes médicos, saberes "do papel” (WACQUANT, 2002), mas também de saberes práticos, que se sobrepõem. É somente na prática que se aprende, por exemplo, o melhor momento para evitar ou tratar bolhas nos pés e as formas de fazer isso, se através do uso de vaselina nos pés, absorventes femininos dentro dos tênis ou de drenagem de bolhas com linha e agulha. E essa prática se desenrola nos encontros com demais ultramaratonistas, ou seja, é um saber adquirido individualmente no interior da coletividade de ultramaratonistas, que só pode ser consolidado de forma prática e coletiva.

$\mathrm{O}$ uso de substâncias, alongamentos e massagens e lembrar-se de familiares ou de causas filantrópicas são exemplos de técnicas de superação da dor observados na prova etnografada, o que aponta para uma dinâmica física e moral desta superação.

As substâncias são utilizadas de acordo com o efeito pretendido e podem ser ingeridas de diferentes formas, sendo reclassificadas e resinificadas em relação à prática da ultramaratona: comprimidos de analgésico ou relaxante muscular, para evitar ou combater dores musculares; carboidratos em gel ou rapadura são usados para "dar mais energia"; cápsulas de cafeína ou copos de café evitam a fadiga e afastam o sono; cápsulas de sal ou alimentos salgados são usados para evitar desidratação, da mesma maneira que os "sorinhos" e a ingestão de água e de bebidas isotônicas formuladas para esportistas; refrigerantes de cola ou fazer uma refeição completa, como o almoço, podem ser usados para combater ou prevenir enjoos. Alongamento e massagens também atuariam diretamente no físico do ultramaratonista. Já as lembranças da família, principalmente de filhos, e de causas filantrópicas pelas quais se comprometeram a correr auxiliam na concentração no objetivo de atingir a linha de chegada. Nenhuma das três técnicas apresentadas, entretanto, deve ser compreendida como exclusivamente física ou exclusivamente mental. Como dito anteriormente, as dimensões que compõem o doer estão imbricadas e não são facilmente desconectadas umas das outras. Além disso, as técnicas só atingem o efeito esperado quando utilizadas sob uma estratégia que é aprendida na relação com outros ultramaratonistas, mas que só é eficiente quando o ultramaratonista tem o conhecimento de seu corpo, dos limites que pode ultrapassar e dos momentos em que deve lançar mão das técnicas aprendidas. $\mathrm{O}$ conhecimento de seu corpo pertence à sua mente, é a força mental bem apurada que é capaz de reconhecer o momento de seguir, de usar determinada técnica ou de parar e desistir daquela prova.

Não apenas as técnicas e estratégias de superação do estar-em-dor são construídas e apreendidas no coletivo de ultramaratonistas e na interação com infor- 
mações e profissionais de saúde, mas o próprio doer é aprendido dentro do coletivo. É o grupo social quem determina a legitimidade de seus sofrimentos. Assim, o ultramaratonista desenvolve classificações sensoriais, através de sua prática e do contato com outros ultramaratonistas e profissionais do esporte, que o informam sobre sua gravidade, se é necessário parar, seguir com ajuda de artifícios ou simplesmente seguir.

\section{Dor-prazer}

Com os momentos de introspecção nas provas, vai-se resolvendo "um monte de problema na cabeça”. Como a análise feita por Le Breton (2010) sobre as escarificações infringidas ao próprio corpo por adolescentes, há um sentido de contenção, de controle do sofrimento emocional através da dor autoinfligida. Ao promover em si mesmo uma dor cujo fim o adolescente tem como prever, ele tem a sensação de poder controlar o sofrimento emocional a que está submetido. "Ferirse para estar menos ferido. Ela opõe a dor ao sofrimento, a lesão física à lesão moral" (LE BRETON, 2010: 36). De modo semelhante, ultramaratonistas creem que sofrimentos emocionais, podem ser suplantados pela dor e prazer suscitados pelos tantos quilômetros de uma prova.

O desejo de superação e de atingir a excitação e o prazer almejado justapõese ao sofrimento que seus praticantes atravessam durante as provas. E o jogo é justamente superar a própria sensação dolorosa para atingir o prazer do percurso e a linha de chegada. Dessa forma, a dor não apenas opõe-se ao prazer, mas ela é necessária para que se atinja o prazer em ser um ultramaratonista.

\section{Dispositivo da dor}

Superar o sofrimento imposto por uma distância extremamente longa em terrenos desnivelados torna um corredor ultramaratonista. Se não há sofrimento, não há o que superar. Sem o sofrimento, não existe o prazer de vencê-lo. Quanto mais difícil ou "dura" é a prova, maior o valor que é conferida a ela e maior o status do ultramaratonista que a completou. Dessa maneira, a relação com o doer não se resume à evitação, mas também à sua incitação. Essa dupla relação com o doer pode ser delineada no que aqui chamamos "dispositivo da dor". Nos moldes do que Foucault (2000) tratou como dispositivo, um conjunto decididamente heterogêneo que engloba discursos, instituições, organizações arquitetônicas, decisões regulamentares, leis, medidas administrativas, enunciados científicos, proposições filosóficas, morais, filantrópicas. Em suma, o dito e o não dito são os elementos do dispositivo. O dispositivo é a rede que se pode tecer entre estes elementos (FOUCAULT, 2000: 244).

Se, por um lado, busca-se evitar e superar o doer, por outro lado, busca-se o doer para então evitá-lo e superá-lo. Dessa maneira, lançam mão de técnicas como, por exemplo, o uso de medicamentos analgésicos momentos antes da largada, que atua não sobre uma dor sentida, mas sim sobre a possibilidade de doer. Em contrapartida, "o fácil não tem graça", como costumam dizer os ultramaratonistas, sem a exposição ao sofrimento não existe desafio a ser vencido, não há nada a ser superado, não se constrói a identidade de ultramaratonista. 


\section{Considerações finais}

Não apenas pela sua extensão em quilômetros que as ultramaratonas envolvem o doer, mas também porque a superação desse doer é necessária para a construção da identidade do ultramaratonista. Uma prova que não doa não é suficiente para um atleta tornar-se ultramaratonista, ou seja, alguém capaz de gerenciar o corpo através do controle da própria mente para concluir toda a distância a que se propôs. Há nessas provas não apenas o endurance físico, mas também endurance moral, que se constrói sobre a oposição dor-prazer e corpo-mente. Assim, ultramaratonistas aprendem com seus pares e profissionais de saúde como doer e como vencer o estar-em-dor participando do jogo de evitação e incitação que compõem o dispositivo da dor nesse esporte.

Recebido em 28 de julho de 2019.

Aprovado em 24 de novembro de 2019.

\section{Referências}

BIRO, David. Is There Such a Thing as Psychological Pain? and Why It Matters. Culture Medicine and Psychiatry, 34 (4): 658-667, 2010.

BOURDIEU, Pierre. Economia das trocas linguísticas. São Paulo: Edusp, 2008. BOURDIEU, Pierre. Questões de Sociologia. Rio de Janeiro: Marco Zero, 1983.

BOURKE, Joanna. The Story of Pain: From Prayer to Painkillers. Oxford: Oxford University Press, 2014.

CONRAD, Peter. The medicalization of society: on the transformation of human conditions into treatable disorders. Baltimore: The Johns Hopkins University Press, 2007.

CSORDAS, Thomas. Corpo/Significado/Cultura. Porto Alegre: EdUFRGS, 2008.

DUARTE, Luiz Fernando Dias. A pulsão romântica e as ciências humanas no Ocidente. Revista Brasileira de Ciências Sociais, 19 (55): 5-18, 2004.

DUARTE, Luiz Fernando Dias. Da vida nervosa nas classes trabalhadoras urbanas. Rio de Janeiro: Jorge Zahar, 1986.

DUARTE, Luiz Fernando Dias. "Investigação antropológica sobre doença, sofrimento e perturbação: uma introdução”. In: DUARTE, Luiz Fernando Dias; LEAL, Ondina Fachel (orgs.). Doença, sofrimento, perturbação: perspectivas etnográficas. Rio de Janeiro: Fiocruz, 1998. pp. 9-27.

DUARTE, Luiz Fernando Dias. "O império dos sentidos: sensibilidade, sensualidade e sexualidade na cultura ocidental moderna”. In: HEILBORN, Maria Luiza 
(org.). Sexualidade: o olhar das ciências sociais. Rio de Janeiro: Jorge Zahar, 1999. pp. 21-30.

ELIAS, Norbert; DUNNING, Eric. A Busca da Excitação. Lisboa: Difel, 1992.

FOUCAULT, Michel. "Sobre a História da sexualidade”. In: Microfísica do poder. Rio de Janeiro: Graal, 2000. pp. 243-27.

HANOLD, Maylon. Beyond the marathon: (des)construction of female ultrarunning bodies. Sociology of Sport Journal, 27 (2): 160-177, 2010.

HENNING, April. Run for Health: Health(icization), Supplements, and Doping in Non-Elite Road Running. Dissertação (Mestrado em Sociologia). University of New York, Nova Iorque, 2014. 188f.

LE BRETON, David. A Sociologia do Corpo. Rio de Janeiro, Vozes, 2010.

LE BRETON, David. Escarificações na adolescência; uma abordagem antropológica. Horizontes Antropológicos, 16 (33): 25-40, 2010.

LUPTON, Deborah. Corpos, prazeres e práticas do eu. Educação e Realidade; 25(2): 15-48, 2000.

MAUSS, Marcel. Sociologia e Antropologia. v. 2. São Paulo: EDU/EDUSP, 1974.

MøLLER, Verner. The doping devil. Helsinki: Books on Demand, 2008.

MORAES, Danielle; CASTIEL, Luis David; RIBEIRO, Ana Paula Alves. "Não" para jovens bombados, "sim" para velhos empinados: o discurso sobre anabolizantes e saúde em artigos da área biomédica. Cadernos de Saúde Pública, 31 (6): 1131-1140, 2015.

ORTEGA, Francisco. "Da ascese à bio-ascese ou do corpo submetido à submissão do corpo". In: RAGO, M; ORLANDI, L. B. L; VEIGA-NETO, A. Imagens de Foucault e Deleuze: ressonâncias nietzchianas. Rio de Janeiro: DP\&A, 2005. pp. 139-73.

SABINO, Cesar; LUZ, Madel. Forma da dor e dor da forma: significado e função da dor física entre praticantes de bodybuilding em academias de musculação do Rio de Janeiro. Physis - Revista de Saúde Coletiva, 24 (2): 467-49o, 2014.

VARGAS, Eduardo Viana. "Os corpos intensivos: sobre o estatuto social do consumo de drogas legais e ilegais”. In: DUARTE, Luiz Fernando Dias; LEAL, Ondina Fachel (orgs.). Doença, sofrimento, perturbação: perspectivas etnográficas. Rio de Janeiro: Fiocruz, 1998. pp. 121-36.

VILLAR, Marcio. Desafiando Limites. Rio de Janeiro: Gaffa Mkt, 2015.

WACQUANT, Loic. Corpo e Alma: Notas Etnográficas de um Aprendiz de Boxe. Rio de Janeiro: Relume Dumará, 2002. 